AGRITECH, Vol. 37, No. 3, Agustus 2017, Hal. 295-301

DOI: http://doi.org/10.22146/agritech.11263

ISSN 0216-0455 (Print), ISSN 2527-3825 (Online)

Tersedia online di https://jurnal.ugm.ac.id/agritech/

\title{
Transesterifikasi In Situ Biji Kemiri (Aleurites moluccana L) Menggunakan Metanol Daur Ulang dengan Bantuan Gelombang Ultrasonik
}

\author{
In Situ Transesterification of Candle Nut (Aleurites moluccana L) using Recovered Methanol by Sonication \\ M. Mahlinda*, Meuthia Busthan \\ Balai Riset dan Standardisasi Industri Banda Aceh, Jl. Cut Nyak Dhien No. 377 Lamteumen Timur, \\ Banda Aceh 23236, Indonesia \\ Email: mahlinibr_aceh@yahoo.com
}

Submisi: 2 September 2015; Penerimaan: 10 Februari 2017

\begin{abstract}
ABSTRAK
Tujuan dari penelitian ini adalah untuk mempelajari penggunaan metanol daur ulang pada reaksi transesterifikasi in situ biji kemiri (Aleurites moluccana L) menjadi biodiesel menggunakan radiasi gelombang ultrasonik. Pengaruh dari rasio metanol daur ulang terhadap biji, jumlah katalis, waktu reaksi dan temperatur telah diteliti. Sifat penting dari biodiesel seperti densitas, viskositas dan bilangan asam telah diuji menurut satandar SNI 7182:2012. Hasil penelitian menunjukkan bahwa rendemen maksimum yang dapat diperoleh adalah $57,85 \%$ pada rasio metanol daur ulang tehadap biji $40: 1$, jumlah katalis $4 \%$, temperatur reaksi $65{ }^{\circ} \mathrm{C}$ dan waktu reaksi 80 menit. Hasil pengujian sifat biodiesel menunjukkan bahwa dua paramater (densitas dan viskositas) telah memenuhi standar SNI 7182:2012, sementara bilangan asam lebih tinggi dari standar maksimum. Dapat disimpulkan bahwa metanol daur ulang cocok untuk memproduksi biodiesel secara in situ transesterifikasi tetapi rendemennya lebih rendah jika dibandingkan dengan penggunaan metanol baru.
\end{abstract}

Kata kunci: Biodiesel; kemiri; transesterifikasi in situ; metanol daur ulang

\begin{abstract}
The purpose of this research was to study the effect of the use of recovered methanol for in situ transesterification reaction candlenut seed (Aleurites moluccana $\mathrm{L}$ ) as a biodiesel bysonication. The influence of the ratio of recovered methanol to seed, catalyst concentration, reaction time and the temperature was investigated. Important properties of biodiesel such as density, viscosity and acid number were checked according to SNI 7182:2012 standards. The result showed that the maximum yield which has been obtained was $57,85 \%$ at recovered methanol to seed ratio $40: 1$, catalyst concentration $4 \%$, reaction temperature $65{ }^{\circ} \mathrm{C}$ and reaction time 80 minutes. The test result of biodiesel properties showed that two parameters (density and viscosity) were conformed to SNI 7182:2012 standards, meanwhile acid value was higher than the maximum standards. In conclusion, the recovered methanol was feasible to produce biodiesel via in situ transesterification but the yield was lower if compared with the use of fresh methanol.
\end{abstract}

Keywords: Biodiesel; candlenut; in situ transesterification; recovered methanol 


\section{PENDAHULUAN}

Berkurangnya pasokan energi berbasis fosil dan semakin meningkatnya penggunaan energi, memicu para peneliti untuk mencari sumber energi terbarukan yang dapat menggantikan pengunaan bahan bakar fosil. Biodiesel merupakan salah satu alternatif pengganti minyak solar yang dapat digunakan secara langsung ke dalam mesin diesel tanpa modifikasi mesin.

Biodiesel didefinisikan sebagai campuran ester monoalkil dari asam lemak rantai panjang yang dalam bahasa Inggris dikenal dengan sebutan Fatty Acid Methyl Ester (FAME) berasal dari bahan baku yang dapat diperbaharui seperti minyak nabati atau lemak hewani (Demirbas, 2009; Ma dan Hanna, 1999). Dibandingkan dengan minyak fosil, biodiesel mempunyai beberapa keuntungan diantaranya dapat diperbaharui, mudah diurai oleh alam (biodegradable), menghasilkan emisi lebih rendah, tidak mengandung racun dan bebas sulfur (Martini dan Shell, 1998). Penggunaan biodiesel dapat memecahkan dua krisis yaitu krisis bahan bakar dan kerusakan lingkungan (Refaat, 2010).

Transesterifikasi in situ merupakan suatu metode baru yang sedang dikembangkan oleh banyak peneliti yang bertujuan untuk memperpendek proses produksi biodiesel. Pada proses transesterifikasi in situ, proses ekstraksi minyak dan reaksi transesterifikasi minyak menjadi biodiesel terjadi secara simultan dalam satu kali proses. Transesterifikasi in situ merupakan penyederhanaan dari proses konvensional dengan menghilangkan proses ekstraksi minyak, degumming dan esterifikasi sehingga proses produksi biodiesel dapat diperpendek (Daryono, 2013; Samuel dan Dairo, 2012). Pada proses ini, ekstraksi minyak, esterifikasi dan transesterifikasi dilakukan dalam satu langkah dengan alkohol berfungsi sebagai pelarut ekstraksi sekaligus sebagai reagent selama proses transesterfikasi in situ berlangsung. Hal ini menyebabkan konsumsi alkohol dengan jumlah yang lebih tinggi dibandingkan proses konvensional. Beberapa penelitian transesterifikasi in situ telah dilakukan menggunakan jumlah metanol yang berbeda-beda berkisar antara 100:1 hingga 1400:1 (Samuel dan Dairo, 2012).

Penggunaan metanol dalam jumlah besar pada proses transesterifikasi in situ akan menimbulkan masalah di kemudian hari seperti meningkatnya biaya produksi untuk pembelian metanol, menghasilkan limbah buangan yang akan menimbulkan pencemaran lingkungan, mudah terjadinya kebakaran, kesulitan dalam transportasi dan penyimpanan serta akan menimbulkan dampak negatif terhadap kesehatan manusia karena metanol bersifat racun (Dhar dan Kirtania, 2009). Untuk memenuhi persyaratan mutu ASTM D6751, sisa metanol dalam biodiesel harus dipisahkan dan dimurnikan (recovery) untuk digunakan kembali karena hampir semua standar yang ada hanya mengizinkan $0,2 \%$ metanol dalam produk akhir (Knothe dkk., 2005). Pada proses transesterifikasi in situ, kandungan biodiesel dan gliserol tidak akan terpisah jika jumlah metanol dalam campuran tersebut masih tinggi, untuk itu setelah proses transesterifikasi in situ selesai metanol harus dipisahkan, salah satunya adalah dengan menggunakan peralatan evaporator.

Reaktor ultrasonik merupakan sebuah peralatan yang bekerja menggunakan gelombang yang tidak mampu dideteksi oleh indera pendengaran manusia karena beroperasi pada frekuensi diatas $20 \mathrm{kHz}$ yang merupakan frekuensi di luar ambang batas pendengaran manusia. Gelombang ini dapat merambat dalam medium padat, cair, dan gas (Cameron dan Skofronick, 1978). Penggunaan reaktor ultrasonik untuk pembuatan biodiesel pertama kali diperkenalkan oleh Hielscher Ultrasonic GmbH pada tahun 2000 menggunakan ultrasonik prosesor yang beroperasi pada rentang frekwensi 18 hingga 20 kHz (Ramachandran dkk., 2013). Gelombang ultrasonik dapat menghasilkan energi mekanik yang dapat digunakan untuk pegadukan minyak dan metanol dalam pembuatan biodiesel. Ketika gelombang ultrasonik mencapai suatu bahan maka akan menimbulkan perenggangan dan pemampatan pada celah antar molekul cairan menyebabkan terbentuknya gelembung-gelembung mikro dalam waktu sangat singkat (kurang dari $1 \times 10^{-7}$ detik). Ketika gelembung tersebut pecah, akan membantu mengecilkan ukuran droplet metanol maupun minyak menjadi $42 \%$ lebih kecil bila dibandingkankan dengan pengadukan konvensional. Pada proses ini, akan menyebabkan jumlah area antar muka kedua fase reaktan bertambah besar sehingga proses pembentukan biodiesel dapat berlangsung lebih cepat (Ji dkk., 2006; Wu dkk., 2007).

Tanaman kemiri (Aleurites moluccana Willd) adalah suatu tanaman yang memilik kandungan minyak tinggi mencapai $55-66 \%$ dari total bobot biji kemiri. Komponen utama penyusun minyak kemiri adalah asam lemak tak jenuh dengan sedikit asam lemak jenuh. Minyak kemiri mempunyai sifat mudah terbakar sehingga dapat digunakan sebagai bahan bakar untuk penerangan. Sekarang telah banyak penelitian untuk merubah minyak kemiri menjadi biodiesel seperti yang dilakukan oleh Aunillah dan Pranowo (2012) dan Lima dkk. (2011).

Penelitian ini bertujuan untuk memproduksi biodiesel dari biji kemiri secara transesterifikasi in situ menggunakan metanol daur ulang dari proses transesterifikasi sebelumnya dengan bantuan gelombang ultrasonik dengan memvariasikan perbandingan molar metanol terhadap bobot biji kemiri, jumlah katalis, waktu proses dan temperatur proses. Respon yang diamati adalah rendemen dan mutu biodesel yang dihasilkan. 


\section{METODE PENELITIAN}

\section{Bahan dan Peralatan}

Bahan yang digunakan pada penelitian ini terdiri dari: biji kemiri yang diperoleh dari pasar lokal di Banda Aceh, metanol daur ulang, chloroform PA (Merck) dan katalis $\mathrm{KOH}$ PA (Merck). Sedangkan peralatan yang digunakan terdiri dari reaktor ultrasonik (Elmasonic E300H, $37 \mathrm{kHz}$ ), rotary evaporator (Laborota 4003), erlenmeyer $500 \mathrm{~mL}$ (Pyrex), labu pemisah $250 \mathrm{~mL}$ (Schott), pengaduk mekanik (SciLOGEX OS20S), blender (Sharp SB-TI 172 G) dan oven (Memmert)

\section{Metode}

Penelitian dilaksanakan di laboratorium proses Balai Riset dan Standardisasi (Baristand) Industri Banda Aceh. Rancangan percobaan yang digunakan pada penelitian ini adalah rancangan acak lengkap faktorial dengan 2 kali ulangan untuk seluruh perlakuan. Penelitian diawali pengujian kadar minyak kemiri di laboratorium kimia umum Baristand Industri Banda Aceh. Selanjutnya dilakukan proses transesterifikasi in situ menggunakan metanol daur ulang dengan variabel:

a. Variabel tetap

- Bobot kemiri: $10 \mathrm{~g}$

- Ukuran kemiri: 30 mesh

- Kadar air: < 1\%

- Perbandingan bobot co-solvent (kloroform) terhadap bobot biji kemiri : $1: 1$

b. Variabel tidak tetap

- Perbandingan bobot metanol terhadap bobot biji kemiri: 10:1, 20:1, 30:1, 40:1, dan 50:1

- Jumlah katalis : 1, 2, 3, 4, dan 5\%

- Temperatur proses : 45, 50, 55, 60 dan $65^{\circ} \mathrm{C}$

- Waktu proses: 50, 60, 70, 80, dan 90 menit

Diagram alir proses transesterifikasi in situ menggunakan metanol daur ulang disajikan pada Gambar 1.

Rendemen biodiesel yang diperoleh dihitung dengan Persamaan 1:

Rendemen biodiesel $(\%)=\frac{\text { Bobot biodiesel }(\mathrm{g})}{\text { Bobot biji kemiri }(\mathrm{g}) \times \text { Kandungan minyak }(\%)} \times 100 \%$

Sedangkan produk biodiesel yang diperoleh dilakukan pengujian mutu sesuai dengan SNI 7182-2012 yang meliputi: uji densitas, viskositas dan uji angka asam. Adapun foto peralatan eksperimen menggunakan reaktor ultrasonik disajikan pada Gambar 2.

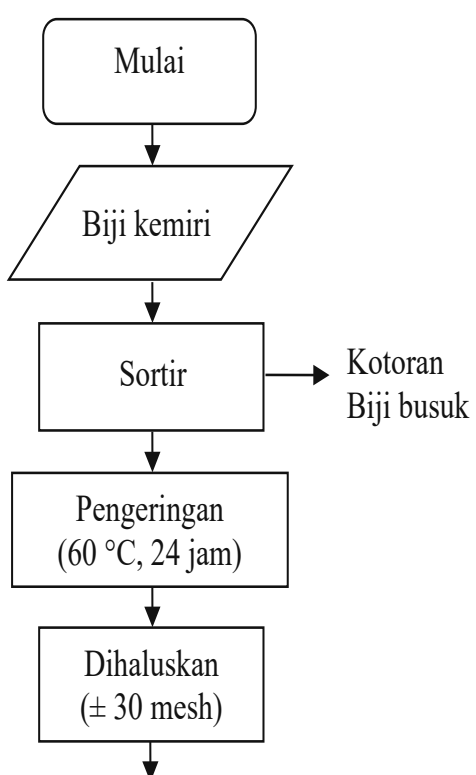

- Metanol daur ulang

- Kloroform

- Katalis $(\mathrm{KOH})$
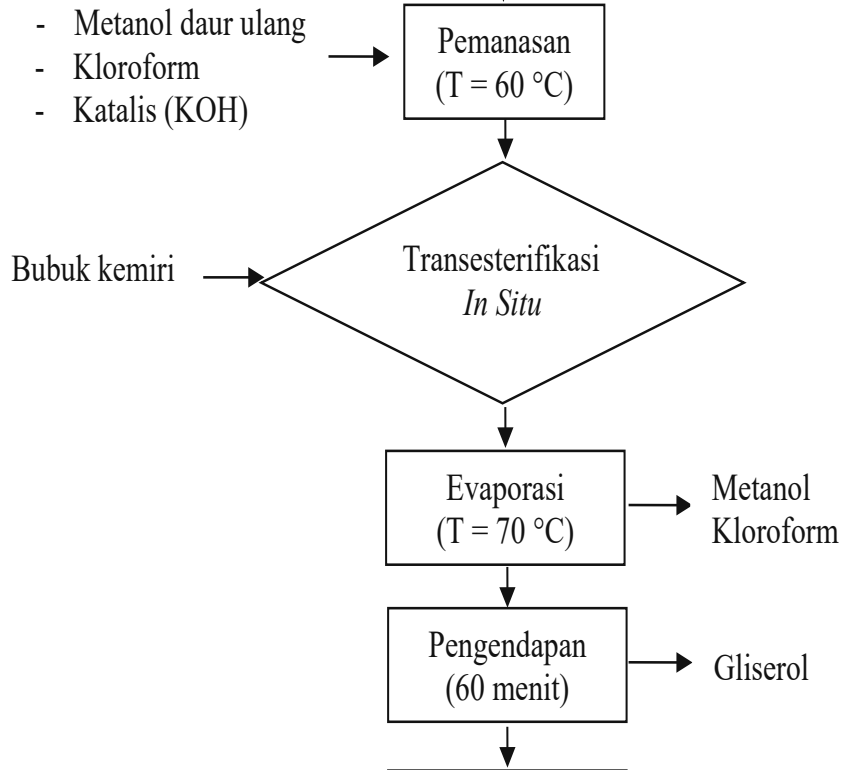

Pencucian

(air hangat)

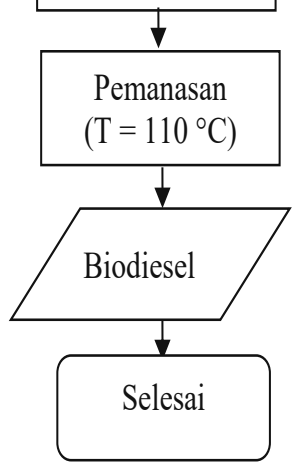

Gambar 1. Diagram alir transesterifikasi in situ menggunakan metanol daur ulang 


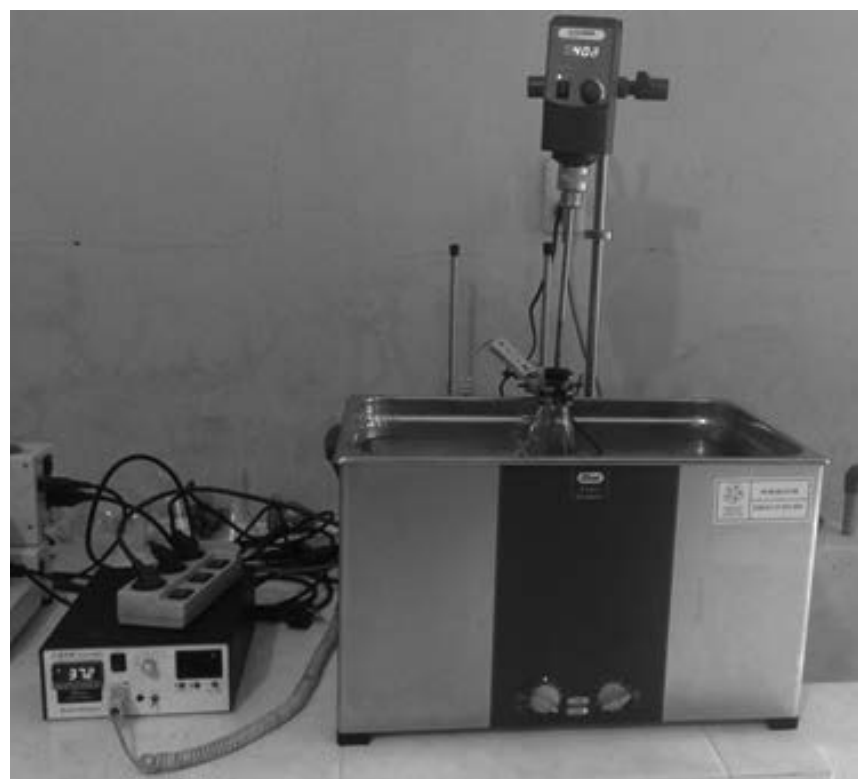

Gambar 2. Peralatan ultrasonik

Peralatan ultrasonik ini mempunyai spesifikasi sebagai berikut: Merk: Elmasonic, type E300H, frekwensi: 37 kHZ, sumber arus: AC 220 volt, daya listrik: 1200 watt dan kapasitas reaktor: 28 liter.

\section{HASIL DAN PEMBAHASAN}

\section{Pengaruh Perbandingan Bobot Metanol:Biji Kemiri terhadap Rendemen Biodiesel}

Salah satu faktor utama yang sangat mempengaruhi rendemen biodiesel yang dihasilkan adalah perbandingan jumlah pelarut (metanol) dan bahan baku. Umumnya, pada proses konvensional memerlukan tiga mol metanol untuk satu mol minyak (Meng dkk., 2008). Proses transesterifikasi in situ berbeda dari proses transesterifikasi konvensional, proses ekstraksi dan transesterifikasi berlangsung dalam satu tahap. Pada proses ini, metanol mempunyai dua fungsi sekaligus yaitu sebagai pelarut pada proses ekstraksi sekaligus berfungsi sebagai reagent pada proses transesterifikasi. Untuk itu diperlukan metanol dalam jumlah lebih besar jika dibandingkan dengan proses konvensional. Metanol dalam jumlah besar tersebut digunakan untuk memastikan bahwa minyak atau lemak akan benar-benar dikonversi ke biodiesel dan dapat menghasilkan rendemen yang lebih tinggi dalam waktu singkat.

Gambar 3 menunjukkan perbandingan bobot biji kemiri dan metanol terhadap rendemen biodiesel yang dihasilkan dengan kondisi proses sebagai berikut: $\mathrm{T}=65^{\circ} \mathrm{C}, \mathrm{t}=80$ menit dan jumlah katalis 4\%. Gambar 3 dapat dilihat bahwa semakin tinggi perbandingan bobot metanol dan biji kemiri, rendemen

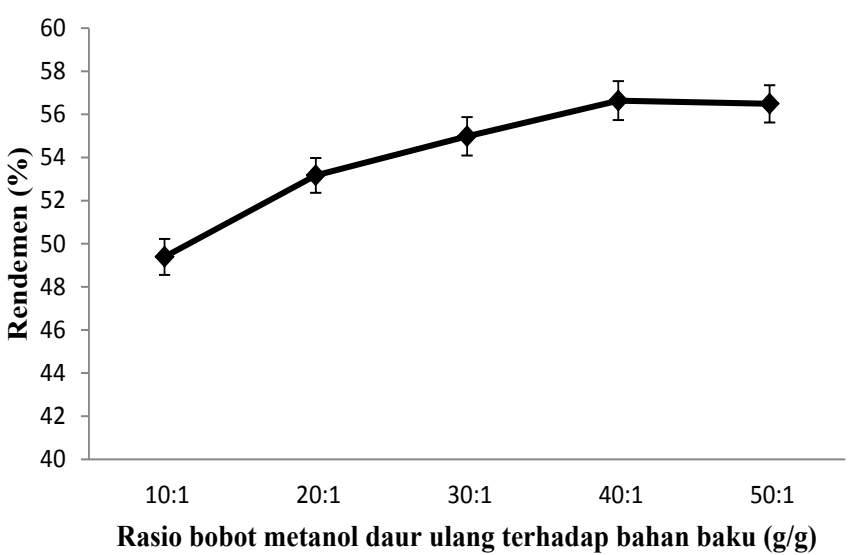

Gambar 3. Pengaruh perbandingan bobot metanol dan biji kemiri terhadap rendemen biodiesel

biodiesel yang diperoleh semakin tingggi. Rendemen tertinggi $(56,64 \%)$ didapat pada perbandingan bobot metanol dan biji kemiri 40:1. Namun pada perbandingan $>40: 1$ akan menghasilkan konversi biodiesel yang sedikit menurun namun masih masuk dalam perolehan rendemen tertinggi.

Transesterifikasi in situ merupakan suatu proses keseimbangan yang memerlukan metanol dalam jumlah besar untuk mendorong reaksi ke arah depan (kanan). Namun kelebihan metanol dapat menurunkan rendemen biodiesel karena meningkatnya kelarutan gliserol. Ketika terdapat gliserol yang berlebihan di dalam larutan akan mendorong proses reaksi kembali ke arah kiri sehingga dapat menurunkan rendemen biodiesel yang dapat dikonversikan (Miao dan $\mathrm{Wu}$, 2006; Barnwal dan Sharma, 2005).

\section{Pengaruh Jumlah Katalis terhadap Rendemen Biodiesel}

Sama seperti proses transesterifikasi konvensional, proses transesterifikasi in situ tidak dapat berlangsung jika tidak ada katalis. Penelitian yang dilakukan oleh Zeng dkk. (2009) menggunakan biji kedelai, hanya dapat menghasilkan rendemen tertinggi sebesar 4,5\% jika menggunakan pelarut (metanol) tanpa penambahan katalis. Katalis asam atau basa berfungsi untuk memecahkan dinding sel bahan baku sehingga metanol dapat mengakses minyak di dalam inti sel, sehingga proses pembentukan biodiesel dapat terjadi lebih cepat (Qian dkk., 2008). Gambar 4 menunjukkan pengaruh jumlah katalis terhadap rendemen biodiesel yang dihasilkan menggunakan metanol daur ulang pada kondisi proses sebagai berikut: $\mathrm{T}=$ $65^{\circ} \mathrm{C}, \mathrm{t}=80$ menit dan perbandingan bobot metanol dan biji kemiri 40:1.

Gambar 4 dapat diketahui bahwa penambahan jumlah katalis $(\mathrm{KOH})$ cukup berpengaruh terhadap rendemen biodiesel yang dihasilkan. Penambahan katalis sebesar $1 \%$ hingga $4 \%$ memberikan pengaruh kenaikan rendemen biodiesel yang sebanding yaitu semakin besar jumlah 


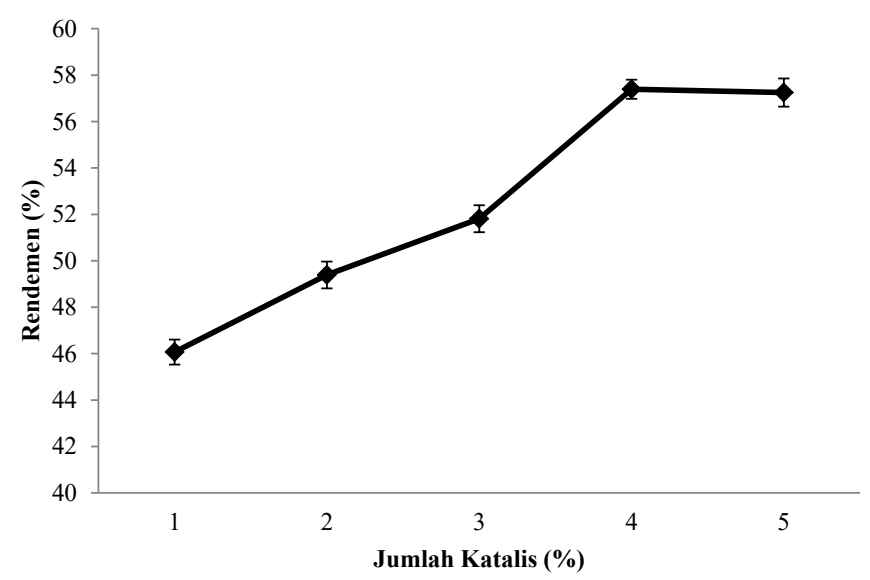

Gambar 4. Pengaruh jumlah katalis terhadap rendemen biodiesel

katalis maka semakin besar juga rendemen yang dihasilkan, rendemen tertinggi $(57,39 \%)$ didapat pada penambahan katalis $4 \%$. Namun dengan penambahan katalis $>4 \%$, rendemen biodiesel yang dihasilkan cenderung menurun. Penggunaan katalis yang rendah menyebabkan tidak mencukupinya dalam mengkatalisasi reaksi sehingga konversi biodiesel menjadi rendah, namun jika jumlah katalis berlebihan akan menyebabkan reaksi penyabunan dan membentuk emulsi yang dapat menghalangi reaksi pembentukan biodiesel sehingga rendemen yang didapat akan menurun juga (Liu dan Wang, 2013).

\section{Pengaruh Temperatur Proses terhadap Rendemen Biodiesel}

Temperatur proses sangat mempengaruhi keberhasilan reaksi pembentuk biodiesel baik menggunakan proses transesterifikasi konvensional maupun proses transesterifiasi secara in situ. Umumnya reaksi transesterifikasi in situ dilakukan pada temperatur antara $40-65{ }^{\circ} \mathrm{C}$ dengan tekanan atmosfer. Gambar 5 menunjukkan pengaruh temperatur proses terhadap rendemen biodiesel yang dihasilkan pada kondisi

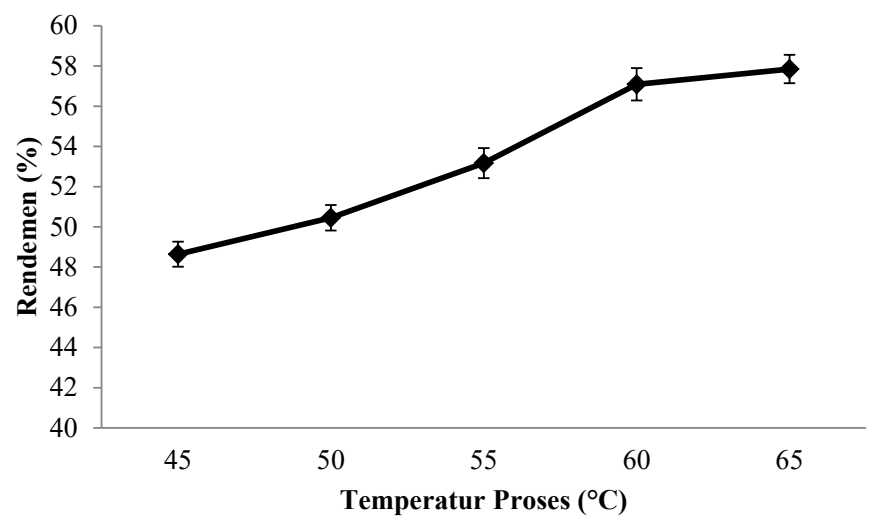

Gambar 5. Pengaruh temperatur terhadap rendemen biodiesel proses dengan $\mathrm{t}=80$ menit, katalis $4 \%$ dan perbandingan bobot metanol dan biji kemiri 40:1.

Gambar 5 dapat dilihat bahwa kenaikan temperatur sangat berpengaruh terhadap besarnya rendemen biodiesel yang diperoleh. Semakin tinggi temperatur semakin besar juga rendemen biodiesel yang diperoleh dan sebaliknya. Rendemen biodiesel tertinggi $57,85 \%$ diperoleh pada temperatur $65^{\circ} \mathrm{C}$, sedangkan temperatur $>65{ }^{\circ} \mathrm{C}$, jika menggunakan peralatan biasa tidak dapat dilakukan lagi karena telah mendekati titik didih metanol. Peningkatan temperatur akan berpengaruh pada peningkatan energi kinetik reaktan untuk mengatasi energi penghalang (energi aktivasi) sehingga tumbukan antara molekul trigliserida dan pelarut (metanol) menjadi lebih efektif menyebabkan produk lebih cepat terbentuk dalam waktu tertentu. Namun, temperatur proses yang lebih tinggi dapat menurunkan rendemen biodiesel, karena temperatur yang tinggi dapat menyebabkan terjadinya reaksi penyabunan di dalam reaktan yang dapat menghalangi reaksi pembentukan biodiesel, disamping itu jika temperatur melebihi $65{ }^{\circ} \mathrm{C}$ menyebabkan metanol mendidih dan menguap (Encinar dkk., 2010).

\section{Pengaruh Waktu Proses terhadap Rendemen Biodiesel}

Waktu proses juga sangat mempengaruhi rendemen biodiesel yang dihasilkan. Secara umum, semakin lama waktu reaksi semakin banyak kadar metil ester yang dihasilkan karena situasi ini akan memberikan kesempatan terhadap molekul-molekul reaktan untuk semakin lama bertumbukan, namun dengan penambahan waktu yang berlebihan dapat menurunkan rendemen biodiesel. Gambar 5 menunjukkan pengaruh waktu proses terhadap rendemen biodiesel yang dihasilkan pada kondisi proses dengan $\mathrm{T}=65^{\circ} \mathrm{C}$, jumlah katalis $4 \%$ dan perbandingan bobot metanol dan biji kemiri 40:1.

Gambar 6 dapat dilihat bahwa semakin lama waktu reaksi akan semakin tinggi juga rendemen biodiesel yang dihasilkan. Rendemen tertinggi $57,85 \%$ didapat dengan

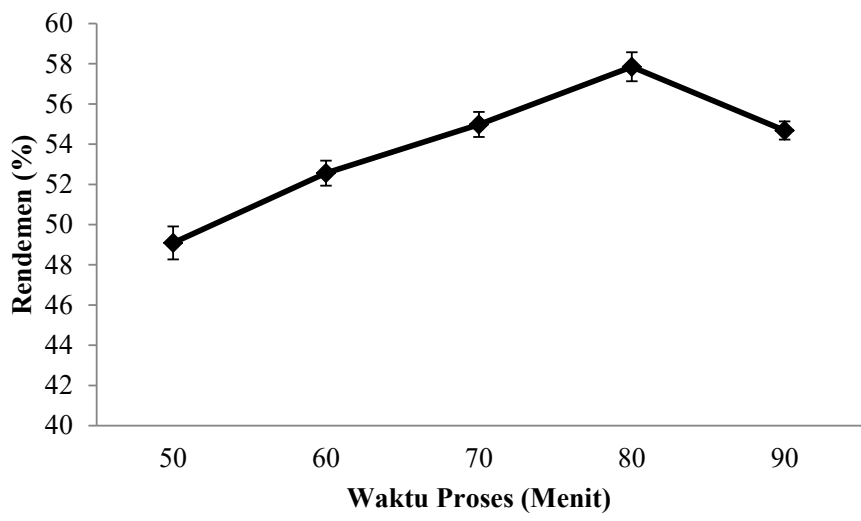

Gambar 6. Pengaruh waktu proses terhadap rendemen biodiesel 
waktu proses 80 menit, sedangkan dengan penambahan waktu proses lebih dari 80 menit rendemen biodiesel akan menurun menjadi 54,68\%.

Penambahan waktu proses yang berlebihan dapat menurunkan rendemen biodiesel, hal ini karena dengan penambahan waktu yang lebih panjang lagi akan menyebabkan terjadinya reaksi balik (reverse reaction) pada saat proses transesterifikasi berlangsung yang dapat menyebabkan terjadinya penyabunan dan akan menghalangi proses pembentukan biodiesel sehingga kadar metil ester akan berkurang (Leung dkk., 2010).

\section{Perbandingan Rendemen Biodiesel Antara Penggunaan Metanol Daur Ulang dan Metanol Baru}

Untuk mengetahui perbandingan rendemen biodiesel antara penggunaan metanol daur ulang dan mentanol baru, dilakukan sebuah penelitian dengan mengacu pada kondisi optimum hasil transesterifikasi in situ menggunakan metanol daur ulang yaitu pada perbadingan bobot metanol:biji kemiri $40: 1$, jumlah katalis $4 \%$, temperatur $65^{\circ} \mathrm{C}$ dan waktu proses 80 menit. Gambar 6 menunjukkan perbandingan rendemen biodiesel antara penggunaan metanol daur ulang dan metanol baru. Berdasarkan data dari Gambar 7 dapat dilihat bahwa penggunaan metanol baru akan menghasilkan rendemen biodiesel lebih tinggi mencapai 68,65\% jika dibandingkan dengan penggunaan metanol daur ulang dengan rendemen tertinggi mencapai 57,85\%. Rendahnya rendemen biodiesel dengan menggunakan metanol daur ulang diduga karena masih adanya pengotor seperti sisa katalis, kloroform dan pengotor lainnya didalam metanol daur ulang tersebut meskipun telah dilakukan proses recovery. Sisa kotoran tersebut dapat menghambat proses pembentukan biodiesel sehingga rendemen biodiesel yang dihasilkan lebih rendah bila dibandingkan dengan penggunaan metanol baru.

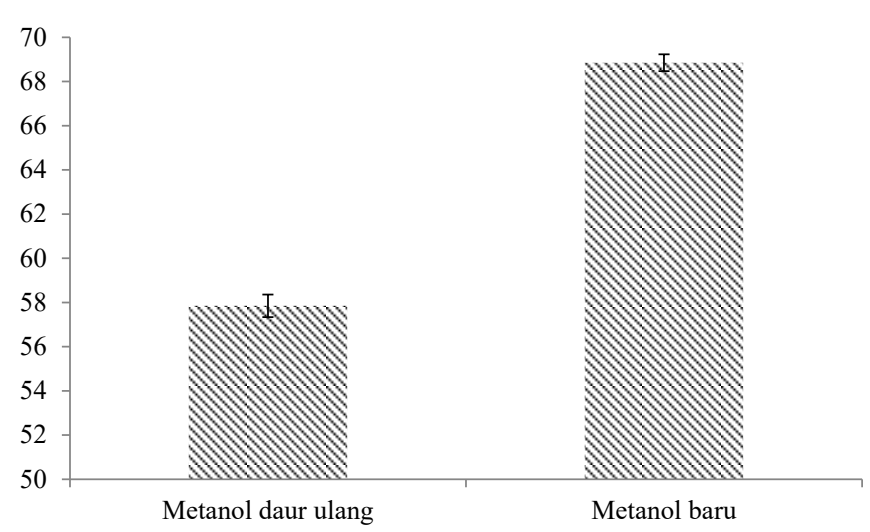

Gambar 7. Perbandingan rendemen biodiesel menggunakan metanol daur ulang dan metanol baru

\section{Pengujian Mutu Biodiesel yang Dihasilkan}

Produk biodiesel dengan rendemen tertinggi dari hasil transesterifikasi in situ menggunakan metanol daur ulang diambil dan dilakukan pengujian mutu yang meliputi uji massa jenis, viskositas dan angka asam. Hasil uji tersebut dibandingankan dengan standar SNI 7182:2012. Hasil uji tersebut disajikan pada Tabel 1 .

Tabel 1. Hasil uji mutu biodiesel yang dihasilkan dan standar SNI $7182: 2012$

\begin{tabular}{lccc}
\hline \multicolumn{1}{c}{ Parameter uji } & Satuan & Hasil uji & SNI \\
\hline Massa jenis $\left(40^{\circ} \mathrm{C}\right)$ & $\mathrm{kg} / \mathrm{m}^{3}$ & 882 & $850-890$ \\
Viskositas kinematik & $\mathrm{mm}^{2} / \mathrm{s}(\mathrm{Cst})$ & 4,68 & $2,3-6,0$ \\
$\left(40^{\circ} \mathrm{C}\right)$ & $\mathrm{mg}-\mathrm{KOH} / \mathrm{g}$ & 0,7 & Maks. 0,6 \\
\hline Angka asam &
\end{tabular}

Tabel 1 dapat dilihat bahwa hasil uji massa jenis produk biodiesel yang dihasilkan sebesar $882 \mathrm{~kg} / \mathrm{m}^{3}$ masih memenuhi persyaratan SNI yaitu antara $850-890 \mathrm{~kg} / \mathrm{m}^{3}$. Massa jenis biodiesel berkaitan dengan komposisi asam lemak dan tingkat kemurnian dari biodiesel, massa jenis akan naik dengan terjadinya penurunan panjang rantai karbon dan peningkatan ikatan rangkap.

Hasil uji viskositas kinematik menunjukkan hasil sebesar 4,68 $\mathrm{mm}^{2} / \mathrm{s}$ masih memenuhi persyaratan SNI yaitu antara 2,3-6,0 $\mathrm{mm}^{2} / \mathrm{s}$. Viskositas kinematik menjadi parameter utama dalam penentuan mutu biodiesel, karena memiliki pengaruh besar terhadap efektivitas biodiesel sebagai bahan bakar. Selain viskositas dan bobot jenis, angka asam juga merupakan salah satu indikator mutu biodiesel. Hal ini disebabkan peningkatan angka asam seperti halnya peningkatan viskositas dan massa jenis adalah hasil aktifitas oksidasi pada metil ester (Canacki dan Gerpen, 2001). Hasil uji angka asam produk biodiesel yang dihasilkan mencapai 0,7 mg-KOH/gr dimana hasil pengujian ini belum memenuhi persyaratan SNI yaitu angka asam maks. 0,6 mg-KOH/g.

\section{KESIMPULAN}

Proses produksi biodiesel dari biji kemiri melalui transesterifikasi in situ menggunakan metanol daur ulang didalam reaktor ultrasonik dapat menghasilkan rendemen tertinggi antara 56,64-57,87\% pada perbandingan bobot metanol dan biji kemiri 40:1, jumlah katalis 4\%, temperatur $65{ }^{\circ} \mathrm{C}$ dan waktu proses 80 menit. Hasil perbandingan antara penggunaan metanol daur ulang dan metanol baru menunjukkan rendemen tertinggi didapat pada penggunaan metanol baru menghasilkan perbedaan rendemen 10,8\%. Hasil pengujian produk biodiesel yang dihasilkan pada kondisi optimum meliputi uji massa jenis, viskositas 
kinematik dan uji angka asam menunjukkan hasil semua parameter yang diuji masih memenuhi persyaratan SNI 71822012, kecuali angka asam lebih tinggi dari batas maksimun yang ditetapkan. Dapat disimpulkan bahwa metanol daur ulang dari proses transesterifikasi sebetulnya dapat digunakan kembali untuk memproduksi biodiesel namun menghasilkan rendemen biodiesel yang lebih rendah bila dibandingkan dengan penggunaan metanol baru.

\section{DAFTAR PUSTAKA}

Aunillah, A. dan Pranowo, D. (2012). Karakteristik biodiesel kemiri sunan (Reutealis trisperma (Blanco) airy shaw) menggunakan proses transesterifikasi dua tahap. Buletin RISTRI 3: 192-200.

Barnwal, B.K. dan Sharma, M.P. (2005). Prospect of biodiesel production from vegetable oil in India. Renewable and Sustainable Energy Reviews 9: 363-378.

Cameron, J.R. dan Skofronick, J.G. (1978). Medical Physics. John Wiley and Sons Inc New York, 253-287.

Canacki dan Gerpen (2001). Biodiesel production from oils and fat with high free fatty acid. Transaction of the American Society of Agricultural Engineers 44: 14291436.

Daryono, D.E. (2013). Biodiesel dari minyak biji pepaya dengan transesterifikasi insitu. Jurnal Teknik Kimia 8: $7-11$.

Demirbas, A. (2009). Progress and recent trends in biodiesel fuels. Energy Conversion and Management 50(1): 1434.

Dhar, R.B. dan Kirtania, K. (2009). Excess methanol recovery in biodiesel production process using a distillation column: A simulation study. Chemical Engineering Research Bulletin 13: 55-60.

Encinar, J.M., Gonzales, J.F., Pardal, A. dan Martinez, G. (2010). Transesterification of Rapeseed oil with methanol in the presence of various co-solvents. Proceeding Venice, Third International Symposium on Energy from Biomass and Waste.

Knothe, G., Gerpen, V.J., Krahl, J. (2005). The Biodiesel Handbook. AOCS Pres. Champaing, Illinois.

Ji, J., Wang, J., Li, Y., Yu, Y. dan Xu, Z. (2006). Preparation of biodiesel with the help of ultrasonic and hydrodynamic cavitation. Ultrasonic 44: 411-414.

Leung, D.Y.C., Wu, X. dan Leung, M.K.H. (2010). A review on biodiesel production using catalyzed transesterification. Applied Energy 87: 1083-1095.
Lima, O.R.J., Gasparini F., Camargo, L.N., Ghani, A.Y., Silva, B.R. dan Oliveira, E.J. (2011). Indian-nut (Aleurites moluccana) and tucum (Astrocaryum vulgare), nonagricultural sources for biodiesel production using ethanol: composition, characterization and optimization of the reactional production conditions. Proceeding of World Renewable Energy Congress 109-116.

Liu, K. dan Wang, R. (2013). Biodiesel production by transesterification of duck oil with methanol in the presence of alkali catalyst. Petroleum and Coall 55: 68-72.

Ma, F. dan Hanna, M.A. (1999). Biodiesel production: a review. Bioresource Technology 70(1): 1-15.

Martini, N. dan Shell, J.S. (1998). Plant Oils as Fuels-Present State of Science and Future Development. SpingerBerlin.

Meng, X., Chen, Y. dan Wang, Y. (2008). Biodiesel production from waste cooking oil via alkali catalyst and its engine test. Fuel Processing Technology 89: 851-857.

Miao, X. dan $\mathrm{Wu}$, Q. (2006). Biodiesel production from heterotrophic microalga oil. Bioresources Technology 97: 841-846.

Qian, J., Wang, F dan Liu, S. (2008). In situ alkaline transeterification of cottonseed oil for production of biodiesel and nontoxid cotton seed meal. Bioresources Technology 18: 9009-9012.

Ramachandran, K., Suganya, N., Gandhi, N.N. dan Renganathan, S. (2013). Recent developments for biodiesel production by ultrasonic assist transesterification using different heterogenous catalyst: A review. Renewable and Sustainable Energy Review 22: $410-418$.

Refaat, A.A. (2010). Different techniques for the production of biodiesel from waste vegetable oil. International Journal of. Environmental Science and Technology 7: 183-213.

Samuel, D.O. dan Dairo, U.O. (2012). A Critical review of Insitu transesterification process for biodiesel production. The Pacific Journal of Science and Technology 13: 72-79.

Wu, P., Yang, Y., Colucci, J.A. dan Grulke, E.A. (2007). Effect of ultrasonication on droplet size in biodiesel mixture. Journal of The American Oil Chemists 'Society 84: $877-884$.

Zeng, J., Wang, X., Zhao, B. dan Wang, Y. (2009). Rapid in situ transeterification of sunflower oil. Industrial and Engineering Chemistry Research 48: 850-856. 